\title{
Editorial prerogatives taken to new heights in matters ARTs
}

\author{
David F. Albertini ${ }^{1}$ \\ Published online: 28 December 2018 \\ (C) Springer Science+Business Media, LLC, part of Springer Nature 2018
}

\section{Science is organized knowledge; Wisdom is organized life Immanuel Kant}

A decade sitting at the helm of JARG has opened this editor's eyes, affirming for once and for all, that anything seems possible in this fledgling-no-more discipline of assisted reproductive technologies we refer to as ARTs. While offered as a subspecialty within the greater realm of reproductive medicine over the past three decades, we practitioners of infertility treatment and management now find our laboratory toolkit extending well into the realm of the Brave New World forecast by Aldous Huxley in his 1932 dystopian novel. The onset of the new year coincides directly with the birth of two gene-edited babies announced by Dr. He Jiankui at the Second International Summit on Human Genome Editing held in Hong Kong in late November 2018. It is fair to say that the truthiness of these claims has yet to be established. While deplored and denigrated by parties widely separated by the varied disciplines taking aim at Dr. He and his colleagues for bringing a presumed note gravity and malfeasance to matters ethical and beyond, the power of technology reigns supreme again thanks to the facile melding of gene editing and baby making à la human ARTs.

Measuring the magnitude of this precocious editorial exercise will take some very thoughtful deliberations by international panelists well versed in their respective camps within and without the changes being scrutinized at the borderline between medicine and health - at least as it pertains to future generations. Ironically, the very foundation upon which human ARTs evolved to fill the void experienced by so many childless couples is being dismantled and reassembled to support the iterations of human genetics that have held steadfast in the quest to

David F. Albertini

eicjarg@gmail.com

1 Center for Human Reproduction, New York, NY, USA identify causative agents - disruptive or not - that will be targets for elimination of disease-causing mutations or the "betterment" of certain individuals, as the eugenics movement so deftly sought to deploy in a forgotten past.

Is it not our responsibility, perhaps prerogative even, to correct genomes from potential reproducers before building a cadre of embryos destined for transfer and offspring yielding? And how sophisticated will gene-editing technology become before resetting the genome of gametes, maternal and/or paternal, on the path to making designer babies?

One thing is for sure as we enter 2019. Despite the hype and manipulation of data that has underscored so many socalled advances in the field of human ARTs, Dr. He's brazen move will forever change the course of reproductive medicine in the future and 2019 will be a revelatory time period to monitor its impact through the eyes of JARG. Why? Because it is often in response to failures-due to human imperfections or technological mishaps - that the true sense of responsibility finally becomes acknowledged in order to rectify and prevent mishaps that have dire consequences.

We begin the year 2019 with an example of one such mishap tainting the track record of ARTs as it relates to one of our most essential activities and responsibilities - the cryostorage of gametes and embryos.

Our lead article by Schiewe and colleagues systemically takes a look at practices past and present having to do with the back door-albeit most important end of the cryobiology spectrum - when time comes to warmthaw those precious samples patients have entrusted us with (Comprehensive assessment of cryogenic storage risk and quality management concerns: best practice guidelines for ART labs https://doi. org/10.1007/s10815-018-1310). This commentary is followed by Dr. Go's assessment of what lies ahead in the field of cryostorage management, a perspective we hope will be shared by our readership going forward.

Given our seasoned dependence on the use of gonadotropin stimulation to pluck as many oocytes as possible from the ovaries of hopeful patients, a fresh and welcomed look at the 
imperfect science of why so many patients fail to yield adequate numbers to proceed through IVF is provided by the group from the University of Sao Paolo in Brazil (Risk factors for inadequate response to ovarian stimulation in assisted reproduction cycles: systematic review https://doi.org/10. 1007/s10815-018-1324). Possible genetic underpinnings to poor ovarian responses and premature ovarian insufficiency are then reported in a series of articles this month (Gonadotropin receptor variants are linked to cumulative live birth rate after in vitro fertilization https://doi.org/10. 1007/s10815-018-1318).

Finally, besides a range of important topics covered this month, we take special pleasure in acknowledging contributions of individuals who have on a regular basis sacrificed time and energy to the maturation of JARG into the respected medium it is today. Without the unselfish efforts of the many reviewers who shape the content and significance of JARG each month, we would not have had the impact on reproductive genetics and ARTs that brought the journal the recognition it received over the past year. Thank you to all for dedicating your expertise to the many authors who have benefitted from your input.

And to members of our editorial board, a special note of gratitude. We wish to thank several members whose tenure has ended including Michael Bloom, Jacques Donnez, Elizabeth McGee, Lisa Pastore, Jeremy Thompson, and Soren Ziebe and take this opportunity to welcome our newest members Denny Sakkas, Bill Catherino, Mara Simonpoulou, and Michael Dahan.

Best wishes from all of us for a happy and healthy 2019 !

Publisher's note Springer Nature remains neutral with regard to jurisdictional claims in published maps and institutional affiliations. 